\title{
Effects of TPX2 gene on radiotherapy sensitization in breast cancer stem cells
}

\author{
CHAOYOU HUANG ${ }^{1}$, ZHENG HAN $^{1}$ and DEHUA WU ${ }^{2}$ \\ ${ }^{1}$ Department of Breast and Thyroid Surgery, Hexian Memorial Hospital of Panyu, Guangzhou, Guangdong 511400; \\ ${ }^{2}$ Department of Radiotherapy, Nanfang Hospital of Southern Medical University, Guangzhou, Guangdong 510515, P.R. China
}

Received September 6, 2016; Accepted April 3, 2017

DOI: $10.3892 / 01.2017 .6277$

\begin{abstract}
The present study explored the link between the targeting protein for Xenopus kinesin-like protein 2 (TPX2) gene and breast tumor stem cells in order to screen novel radiosensitizers. Expression of TPX2 protein and gene in breast cancer cells was analyzed by western blot analysis and RT-PCR. Three kinds of broad-spectrum sensitizers were selected and their effects on radiotherapy were analyzed by immunohistochemistry in breast tumor stem cells. TPX2 gene and protein were expressed in breast tumor cells and increased gradually along with the expression of cancer cell differentiation; $25 \mathrm{mg} / \mathrm{l}$ lovastatin showed best radio-sensitizing effects on breast cancer cells. Furthermore, immunohistochemical results showed that the positive rate of breast cancer cells processed by $25 \mathrm{mg} / \mathrm{l}$ lovastatin were significantly decreased. In conclusion, TPX2 gene is closely related to the development of breast cancer stem cells. Moreover, the sensitizing effects of lovastatin on breast tumor stem cells are the result of its influence on the TPX2 gene.
\end{abstract}

\section{Introduction}

Breast cancer is one of the most common malignant tumors of females with high incidence and high mortality $(1,2)$. It was traditionally believed that tumor was originated from cell mutation and could grow unlimitedly. However, theories on tumor stem cells have extended knowledge on tumor cells, indicating that tumor develops from tumor stem cells in tissues $(3,4)$. The above recent theory, not only explained biological behavior of breast cancer cells, but also provided new research directions for tumor treatment.

Radiotherapy involves X- or gamma-ray treatment onto tumor region and is one of the main methods of treating tumor.

Correspondence to: Dr Chaoyou Huang, Department of Breast and Thyroid Surgery, Hexian Memorial Hospital of Panyu, 2 East Qinghe Road, Guangzhou, Guangdong 511400, P.R. China

E-mail: huang_chaoyou1@163.com

Key words: targeting protein for Xenopus kinesin-like protein 2 gene, breast cancer stem cells, lovastatin, radiosensitizer
The rays interact with molecules (mainly water molecules) in tumor cells to produce cytotoxic $\mathrm{OH}$-free radical resulting in cell death or apoptosis (5). However, during conventional radiotherapy, resistance of cancer cells towards rays is commonly observed $(6,7)$. Therefore, seeking strategies to improve breast cancer radiosensitivity is a recent hot spot in radiotherapy research against tumor.

Targeting protein for Xenopus kinesin-like protein 2 (TPX2) gene, also called XKIP2-targeted protein, is necessary for the microtubule structuring process of cell kinetochore (8-10). Abundant research in recent years has shown that TPX2 gene is closely related with the development of cancer cells such as lung, colon and cervical cancer cells (11). However, there are few studies on the association between TPX2 gene and breast cancer cells.

To the best of our knowledge, the present study examined for the first time TPX2 expression in breast tumor stem cells and investigated the association between TPX 2 gene and breast tumor stem cells. The present study also involved exploration of radiotherapy with various sensitizers on breast stem cells by targeting the TPX2 gene.

\section{Materials and methods}

Experimental materials. Bcap37, MCF7, SKBR3 and MDAMB231 breast cancer cells were purchased from the American Type Culture Collection (ATCC) cell bank (Manassas, VA, USA). Tissue samples were collected from 55 cases of breast cancer cells removed during surgeries from March 2014 to June 2016 in the Hexian Memorial Hospital of Panyu (Guangzhou, China). The samples were confirmed by biopsy. According to clinical staging by International Federation of Gynecology and Obstetrics (FIGO). There were $12,13,9$ and 21 cases of I-IV stages, respectively. The patients were aged 29-55 years with an average of 38.4 \pm 3.9 years. Normal breast cells were collected for comparison. Compounds with spectral sensitization such as docetaxel, lovastatin and $\beta$-santalene were obtained.

Extraction of cell total proteins. Specific experimental methods were previously described (12). Extracted proteins were saved at $-80^{\circ} \mathrm{C}$.

Western blot analysis. Specific experimental methods were carried out as previously described (13). 
Table I. TPX2 protein relative expression in four types of breast cancer cells (mean \pm SD).

\begin{tabular}{lccccc}
\hline Variables & Normal cell & Bcap37 & MCF7 & SKBR3 & MDAMB231 \\
\hline TPX2 (OD) & $0.028 \pm 0.012$ & $0.318 \pm 0.023$ & $0.377 \pm 0.019$ & $0.373 \pm 0.018$ & $0.374 \pm 0.022$ \\
$\beta$-actin (OD) & $0.93 \pm 0.13$ & $0.89 \pm 0.11$ & $0.93 \pm 0.22$ & $0.95 \pm 0.13$ & $0.97 \pm 0.21$ \\
Relative expression & $0.003 \pm 0.001^{\mathrm{a}}$ & $0.357 \pm 0.043^{\mathrm{b}}$ & $0.406 \pm 0.093^{\mathrm{b}}$ & $0.393 \pm 0.025^{\mathrm{b}}$ & $0.386 \pm 0.036^{\mathrm{b}}$ \\
\hline
\end{tabular}

${ }^{\mathrm{a}, \mathrm{b}}$ In one-way ANOVA among groups, the same letter indicated $(\mathrm{P}>0.05)$ no statistical significance; different letters indicated $(\mathrm{P}<0.05)$ statistical significance. Same below. TPX2, targeting protein for Xenopus kinesin-like protein 2.

Extraction of total RNA, detection and determination of purity. Experimental methods were conducted as in the literature (14), with some modifications. Extracted proteins were saved at $-80^{\circ} \mathrm{C}$.

Radiotherapy experiments on the sensitizing compounds. Docetaxel, lovastatin and $\beta$-santalene of the same concentration $(20 \mathrm{mg} / \mathrm{l})$ were prepared to function in Bcap37 breast cancer cells. Sensitizing compounds of the same concentration $(10,15,20,25,30,40$ and $50 \mathrm{mg} / \mathrm{l})$ were prepared to investigate effects of concentration on breast cancer cells (15).

Grouped processing of sensitization. Two microliters of culture and buffer solutions were added to group A for comparison. Different sensitizers at a rate of $20 \mathrm{mg} / \mathrm{l}$ were added to group $\mathrm{B}$. In group $\mathrm{C}$ no sensitizer was given and underwent radiotherapy only. After the experiment, the cell apoptotic rate was recorded by flow cytometry (16).

Radiotherapy and flow cytometry. Specific experimental process was carried out as published (15).

Immunohistochemistry experiment. For detection of TPX2 expression in breast tissues, we performed inmmunohistochemical staining according to a previous study (17).

Statistical analysis. Experimental data were analyzed by SPSS software (Chicago, IL, USA). Differences among groups underwent homogeneity test for variance and t-test; testing level was $\alpha=0.05$. ( $P<0.05$ was considered to indicate a statistically significant difference).

\section{Results}

Detection of TPX2 protein expression in different breast cancer cells by western blot analysis. TPX2 protein expression in four types of breast cancer cells, Bcap37, MCF7, SKBR3 and MDAMB231 were detected by western blot analysis. Normal breast cells were used for comparison, and the OD value ratio of TPX 2 and $\beta$-actin referred to TPX 2 protein relative expression. By combining markers, it was confirmed that the bands between a molecular weight of 100 and $43 \mathrm{kDa}$ were TPX2 protein and $\beta$-actin (Fig. 1). It was observed that TPX2 was expressed in the four types of breast cancer cells but not expressed in the normal cells. This experiment compared the detected OD values with image scanning and analyzing software and conducted statistical processing. Table I shows

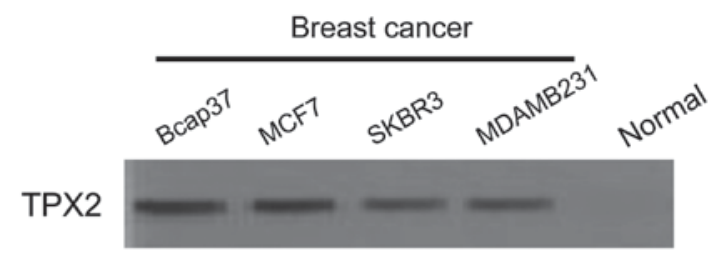

$\beta$-actin

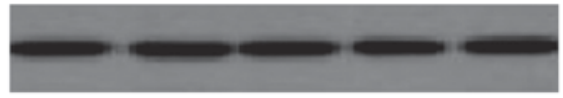

Figure 1. Targeting protein for Xenopus kinesin-like protein 2 (TPX2) expression in different breast cancer cells.

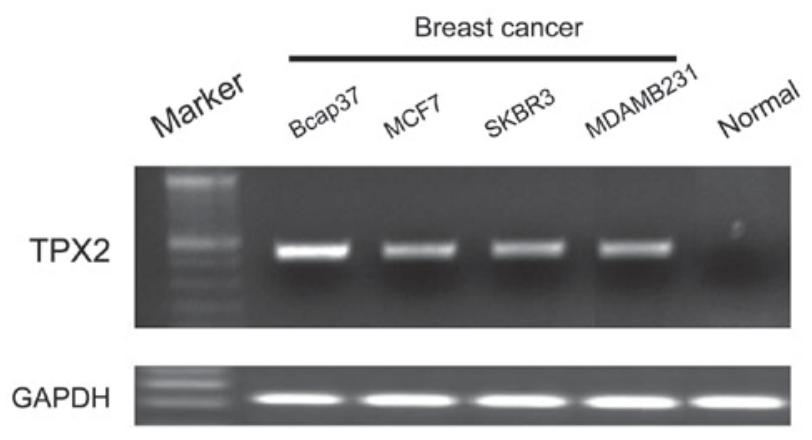

Figure 2. Targeting protein for Xenopus kinesin-like protein 2 (TPX2) mRNA expression in different breast cancer cells.

that TPX2 protein expression in four types of breast cancer cells was significantly higher than that in normal cells $(0.003 \pm 0.001)$, but TPX2 protein expression between each pair of breast cancer cells had no statistical significance $(\mathrm{P}>0.05)$.

Detection of TPX2 mRNA expression in different breast cancer cells by RT-PCR. TPX2 mRNA expression in Bcap37, MCF7, SKBR3 and MDAMB231 was detected by RT-PCR. Normal breast cells were used for comparison, and OD value ratio of TPX2 and GAPDH referred to TPX2 gene expression. It is clear from Fig. 2 that TPX2 mRNA expression was similar to its protein expression in that it was expressed in the four types of breast cancer cells but not expressed in the normal cells. This experiment compared the detected OD values with image scanning and analyzing software and statistical processing was conducted. The TPX 2 mRNA expression (Table II) in the four types of breast cancer cells $(0.536 \pm 0.039$ on average $)$ was 
Table II. TPX mRNA expression in different breast cancer cells (mean \pm SD).

\begin{tabular}{lccccc}
\hline Variables & Normal cells & Bcap37 & MCF7 & SKBR3 & MDAMB231 \\
\hline TPX2 (OD) & $0.004 \pm 0.012$ & $0.464 \pm 0.034$ & $0.520 \pm 0.028$ & $0.478 \pm 0.017$ & $0.499 \pm 0.052$ \\
GAPDH (OD) & $0.86 \pm 0.11$ & $0.84 \pm 0.18$ & $0.90 \pm 0.28$ & $0.93 \pm 0.15$ & $0.89 \pm 0.17$ \\
Relative expression & $0.005 \pm 0.002^{\mathrm{a}}$ & $0.553 \pm 0.023^{\mathrm{b}}$ & $0.578 \pm 0.091^{\mathrm{b}}$ & $0.514 \pm 0.033^{\mathrm{b}}$ & $0.561 \pm 0.062^{\mathrm{b}}$ \\
\hline
\end{tabular}

a,b In one-way ANOVA among groups, the same letter indicated $(\mathrm{P}>0.05)$ no statistical significance; different letters indicated $(\mathrm{P}<0.05)$ statistical significance. TPX2, targeting protein for Xenopus kinesin-like protein 2.

Table III. Comparison of radiotherapy effects of three types of broad-spectrum sensitizers on breast cancer stem cells (cell apoptosis rate, \%; mean $\pm \mathrm{SD}$ ).

\begin{tabular}{lccc}
\hline Groups & Docetaxel & Lovastatin & $\beta$-santalene \\
\hline A (control) & $0.5 \pm 0.02$ & $0.7 \pm 0.05$ & $0.4 \pm 0.03$ \\
B (adding medicine) & $0.6 \pm 0.12$ & $0.3 \pm 0.11$ & $3.3 \pm 0.08$ \\
C (radiotherapy) & $15.2 \pm 0.22^{\mathrm{a}, \mathrm{b}}$ & $21.3 \pm 1.21^{\mathrm{a}, \mathrm{b}}$ & $6.9 \pm 0.52^{\mathrm{a}, \mathrm{b}}$ \\
D (radiotherapy and adding medicine) & $18.5 \pm 1.11^{\mathrm{a}-\mathrm{c}}$ & $33.2 \pm 2.10^{\mathrm{a}-\mathrm{c}}$ & $11.3 \pm 1.15^{\mathrm{a}-\mathrm{c}}$ \\
\hline
\end{tabular}

${ }^{\mathrm{a} C}$ Compared with group $\mathrm{A}, \mathrm{P}<0.05$; ${ }^{\mathrm{b}}$ compared with group $\mathrm{B}, \mathrm{P}<0.05$; ${ }^{\mathrm{c}}$ compared with group $\mathrm{C}, \mathrm{P}<0.05$.

Table IV. Comparison of radiotherapy effects of lovastatin at different concentrations on breast cancer stem cells (concentration, $\mathrm{mg} / \mathrm{l}$; cell apoptosis rate, \%; mean $\pm \mathrm{SD}$ ).

\begin{tabular}{|c|c|c|c|c|c|c|c|}
\hline \multirow[b]{2}{*}{ Groups } & \multicolumn{7}{|c|}{ Concentrations (mg/l) } \\
\hline & 10 & 15 & 20 & 25 & 30 & 40 & 50 \\
\hline $\mathrm{C}$ (radiotherapy) & $21.5 \pm 1.21$ & $19.6 \pm 1.42$ & $22.8 \pm 1.11$ & $18.1 \pm 1.32$ & $19.4 \pm 1.47$ & $20.8 \pm 2.01$ & $20.2 \pm 1.96$ \\
\hline $\begin{array}{l}\mathrm{D} \text { (radiotherapy } \\
\text { and adding medicine) }\end{array}$ & $25.4 \pm 2.12^{\mathrm{a}}$ & $30.4 \pm 2.31^{\mathrm{a}}$ & $35.6 \pm 2.51^{\mathrm{a}}$ & $38.7 \pm 2.12^{\mathrm{a}}$ & $38.9 \pm 1.58^{a}$ & $37.8 \pm 2.45^{\mathrm{a}}$ & $38.2 \pm 2.66^{\mathrm{a}}$ \\
\hline
\end{tabular}

${ }^{\mathrm{a} C o m p a r e d ~ w i t h ~ g r o u p ~} \mathrm{C}, \mathrm{P}<0.05$.

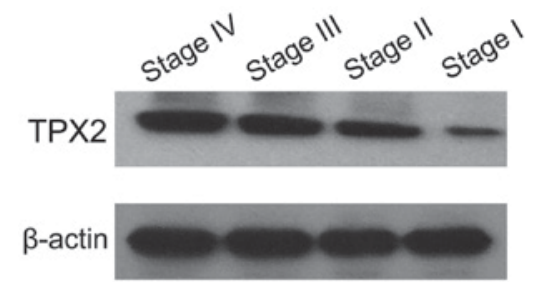

Figure 3. Targeting protein for Xenopus kinesin-like protein 2 (TPX2) mRNA expression in breast cancer cells at different clinical stages.

significantly higher than that in normal cells $(0.005 \pm 0.002)$, but TPX2 mRNA expression between each pair of breast cancer cells had no statistical significance $(\mathrm{P}>0.05)$.

Detection of TPX2 expression in breast cancer cells at various differentiation stages by western blot analysis. TPX2 expression in breast cancer cells at the various differentiation stages was detected by western blot analysis to investigate TPX2 protein changes in the development of breast cancer cells.
Experimental results are shown in Fig. 3. The results showed that TPX2 protein expression at stages I-IV was significantly increased along with the increased of differentiation stages.

Investigation on radiotherapy effects on three types of broad-spectrum sensitizers. In the present study, in comparison to the control group, docetaxel and lovastatin produced less effect on breast cancer cells confirming that cytotoxicity of the two compounds was not strong. However, $\beta$-santalene between two groups had no significant differences, reflecting its strong cytotoxicity. Furthermore, lovastatin had the strongest effects. By comparing three kinds of sensitizers, it was observed that lovastatin had little cytotoxicity but obvious radiotherapy improving effects; thus, it is a relatively reasonable radiotherapy sensitizer on breast cancer cells. As a result, lovastatin was chosen to investigate the effects of different concentration on breast cancer cells (Tables III and IV).

Immunohistochemical results of different groups. Cells undergoing various processing were used as research subjects, 
A
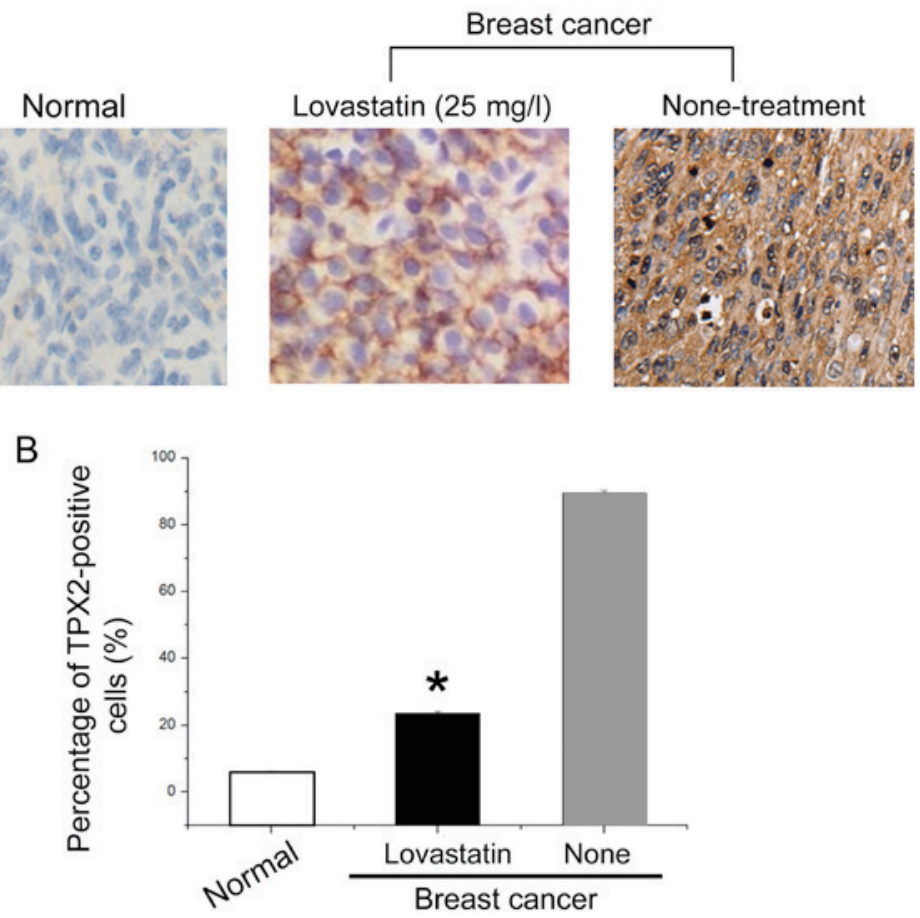

Figure 4. Immunohistochemical staining of targeting protein for Xenopus kinesin-like protein 2 (TPX2) in different groups. (A) Immunohistochemical results. $T P X 2$-negative cells are blue; TPX2-positive cells are brown. (B) Counting results of $T P X 2$-positive cells undergoing various processing. ${ }^{*} \mathrm{P}<0.05$, compared with 'none' group.

and TPX2 protein expression in the cells of different groups were detected by immunohistochemistry. Fig. 4A shows that TPX2 protein-positive rate of breast cancer cells processed by $25 \mathrm{mg} / 1$ lovastatin were significantly lower than that of normal cancer cells. Counting results of positive cells (Fig. 4B) indicated that TPX2 protein positive rate of breast cancer cells processed by $25 \mathrm{mg} / \mathrm{l}$ lovastatin was $23.6 \%$, while TPX2 protein-positive rate of breast cancer cells in the control group was $89.5 \%$. Thus, processing with $25 \mathrm{mg} / 1$ lovastatin improved radiotherapy sensitization significantly.

\section{Discussion}

As living standards improve and dietary habits change, a significant rise in the incidence of breast cancer has been recorded. Although theories on tumor stem cells have improved knowledge on tumor cells, findings suggest new medical directions (18). Breast cancer is a malignant tumor and there is a possibility that incidence and cell migration may occur following surgery. Therefore, treatment methods for breast cancer have no obvious improvement yet, and it is imperative that new treatment initiatives are identified. Advances in life sciences with regard to treating cancer based on genetics has gradually become a research focus (19).

TPX2 gene is a microtubule-associated protein, and research in recent years has shown that it is closely related with the development of multiple cancer cells (20) including breast cancer. Further, radiotherapy has the ability to inhibit cancer cell proliferation but is very cytotoxic. Therefore, seeking a TPX2 gene-targeted compound sensitizer for radiotherapy on breast cancer may be an effective curative method that could alleviate associated side effects. In the present study, we first explored the relationship between TPX2 gene and breast cancer cells, then used three broad-spectrum sensitizers to conduct radiotherapy in vitro to identify the interactive relations between sensitizer and TPX2 gene (21).

By analyzing the relationship between TPX2 gene and breast cancer cells, using western blot analysis and RT-PCR, the present study revealed that TPX2 gene and protein were hardly expressed in normal breast cells but were expressed significantly more in all four types of breast cancer cells. However, expressions in various breast cancer cells were not significantly different. It showed that if TPX2 gene and protein were detected in breast cells, malignant pathological changes could probably exist. This experiment also investigated TPX2 protein expression in breast cancer cells at various differentiation stages and found that TPX 2 protein expression increased significantly along with the increase in differentiation stages, which further indicated TPX2 gene is closely related to the development and deteriorating severity of breast tumor cells. Moreover, monitoring TPX2 gene expression in tumor tissues could evaluate tumor severity and prove useful in the prediction and prognostic treatment of the disease.

After confirming the relationship between TPX2 gene and breast cancer stem cells, the present study selected three kinds of broad-spectrum sensitizers, docetaxel, lovastatin and $\beta$-santalene in threatment with breast cancer cells by conducting radiotherapy in vitro. This experiment compared three kinds of sensitizers and found that docetaxel and lovastatin had little cytotoxicity when no radiotherapy was conducted, while lovastatin had the strongest sensitizing effects and the highest cell apoptotic rate. Therefore, lovastatin was chosen as the sensitizer of radiotherapy for breast cancer. Further effects of lovastatin at different concentrations 
on radiotherapy were investigated and it was found that the cell apoptotic rate was the highest at $25 \mathrm{mg} / \mathrm{l}$ concentration. Since association between TPX2 gene and breast tumor stem cells have been confirmed and lovastatin has significant sensitizing radiotherapy effects on breast tumor stem cells, our research group suspected that lovastatin affects TPX2 gene expression to increase the death rate of cancer cells. However, further investigation is required.

\section{Acknowledgements}

This study was supported by the Medical Science and Technology Research of Guangdong Province (no. A2015033).

\section{References}

1. Sankaranarayanan R and Swaminathan R (eds): Cancer Survival in Africa, Asia, the Caribbean and Central America. Vol 162. IARC Scientific Publications, Lyon, pp23-31, 2011.

2. Li Y, Burns JA, Cheney CA, Zhang N, Vitelli S, Wang F, Bett A, Chastain M, Audoly LP and Zhang ZQ: Distinct expression profiles of Notch-1 protein in human solid tumors: implications for development of targeted therapeutic monoclonal antibodies. Biologics 24: 163-171, 2010.

3. Leong SP, Shen ZZ, Liu TJ, Agarwal G, Tajima T, Paik NS, Sandelin K, Derossis A, Cody H and Foulkes WD: Is breast cancer the same disease in Asian and Western countries? World J Surg 34: 2308-2324, 2010.

4. Matsuda T, Marugame T, Kamo K, Katanoda K, Ajiki W and Sobue T; Japan Cancer Surveillance Research Group: Cancer incidence and incidence rates in Japan in 2004: based on data from 14 population-based cancer registries in the Monitoring of Cancer Incidence in Japan (MCIJ) Project. Jpn J Clin Oncol 40: 1192-1200, 2010.

5. Matsuda T, Marugame T, Kamo K, Katanoda K, Ajiki W and Sobue T; Japan Cancer Surveillance Research Group: Cancer incidence and incidence rates in Japan in 2005: based on data from 12 population-based cancer registries in the Monitoring of Cancer Incidence in Japan (MCIJ) project. Jpn J Clin Oncol 41: 139-147, 2011.

6. Zorba A, Buosi V, Kutter S, Kern N, Pontiggia F, Cho YJ and Kern D: Molecular mechanism of Aurora A kinase autophosphorylation and its allosteric activation by TPX2. eLife 3: e02667, 2014.

7. Petry S, Groen AC, Ishihara K, Mitchison TJ and Vale RD: Branching microtubule nucleation in Xenopus egg extracts mediated by augmin and TPX2. Cell 152: 768-777, 2013.
8. Scholz C and Wagner E: Therapeutic plasmid DNA versus siRNA delivery: common and different tasks for synthetic carriers. J Control Release 161: 554-565, 2012.

9. Silva SM, Moreira HC and Canavarro MC: Examining the links between perceived impact of breast cancer and psychosocial adjustment: the buffering role of posttraumatic growth Psychooncology 21: 409-418, 2012.

10. Cohen M and Numa M: Posttraumatic growth in breast cancer survivors: a comparison of volunteers and non-volunteers. Psychooncology 20: 69-76, 2011.

11. O'Shaughnessy J, Osborne C, Pippen JE, Yoffe M, Patt D, Rocha C, Koo IC, Sherman BM and Bradley C: Iniparib plus chemotherapy in metastatic triple-negative breast cancer. N Engl J Med 36: 205-214, 2011.

12. Shimura T, Takenaka Y, Fukumori T, Tsutsumi S, Okada K, Hogan V, Kikuchi A, Kuwano H and Raz A: Implication of galectin-3 in Wnt signaling. Cancer Res 65: 3535-3537, 2005.

13. Gürtler A, Kunz N, Gomolka M, Hornhardt S, Friedl AA, McDonald K, Kohn JE and Posch A: Stain-Free technology as a normalization tool in Western blot analysis. Anal Biochem 433: 105-111, 2013.

14. Elbers A, Meiswinkel R, van Weezep E, Sloet van OldruitenborghOosterbaan M and Kooi B: Schmallenberg virus detected by RT-PCR in Culicoides biting midges captured during the 2011 epidemic in the Netherlands. Emerg Infect Diseases 433: 105-111, 2013.

15. Vollebergh MA, Jonkers J and Linn SC: Genomic instability in breast and ovarian cancers: translation into clinical predictive biomarkers. Cell Mol Life Sci 69: 223-245, 2012.

16. Tutt A, Robson M, Garber JE, Domchek SM, Audeh MW, Weitzel JN, Friedlander M, Arun B, Loman N, Schmutzler RK, et al: Oral poly(ADP-ribose) polymerase inhibitor olaparib in patients with $B R C A 1$ or $B R C A 2$ mutations and advanced breast cancer: a proof-of-concept trial. Lancet 376: 235-244, 2010.

17. Blanco I, Kuchenbaecker K, Cuadras D, Wang X, Barrowdale D, de Garibay GR, Librado P, Sánchez-Gracia A, Rozas J, Bonifaci N, et al: Assessing associations between the AURKAHMMR-TPX2-TUBG1 functional module and breast cancer risk in BRCA1/2 mutation carriers. PLoS One 10: e120020, 2016.

18. Neumayer G, Belzil C, Gruss OJ and Nguyen MD: TPX2: of spindle assembly, DNA damage response, and cancer. Cell Mol Life Sci 71: 3027-3047, 2014.

19. Hsu HT, Dodd MJ, Guo SE, Lee KA, Hwang SL and Lai YH: Predictors of exercise frequency in breast cancer survivors in Taiwan. J Clin Nurs 20: 1923-1935, 2011.

20. Newlaczyl AU and Yu LG: Galectin-3 - a jack-of-all-trades in cancer. Cancer Lett 313: 123-128, 2011.

21. McGuire R, Waltman $\mathrm{N}$ and Zimmerman L: Intervention components promoting adherence to strength training exercise in breast cancer survivors with bone loss. West J Nurs Res 33: 671-689, 2011. 